\title{
¿Raros o fantásticos?... lo insólito en las ficciones distanciadas de Lautréamont, Felisberto Hernández y Mario Levrero
}

Rare or fantastic? ... the unusual in the fictions distanced from Lautréamont, Felisberto Hernández and Mario Levrero

DOI 10.5377/rct.v0i24.7881

Wilfredo Illas ${ }^{1}$

Mauricio Grandón ${ }^{2}$

\section{RESUMEN}

Desde los postulados de la Estética de la Recepción, se pretende dilucidar un posible horizonte de expectativas para dar cuenta de instancias comprensivas en torno a tres textos: Canto III de Maldoror, La casa inundada y El crucificado del Conde de Lautréamont, Felisberto Hernández y Mario Levrero respectivamente, cuya experiencia de lectura se verá reconstruida a la luz de los aportes de Darko Suvin, Ángel Rama y Heber Benítez atendiendo tres categorías conceptuales: lo raro, fantástico y distanciado, las cuales suscitan posibilidades dialógicas para el concierto de otros aportes teóricos que coadyuvan en la configuración de las tramas organizativas y argumentativas que cohesionan este discurso, a saber: trama teórica, contextual y metodológica. Dado el carácter realimentativo, inacabado y aproximativo, este trabajo no pretende dar conclusiones, por el contrario, pretende propiciar un escenario reflexivo que permita advertir una de las múltiples posibilidades de lectura que estos textos despliegan.

Palabras clave: Raro, fantástico, ficciones distanciadas, maravilloso, estética de la recepción.

\footnotetext{
${ }^{1}$ Doctor en Educación por la Universidad de Carabobo, Venezuela. Doctor en Literatura Latinoamericana en la Universidad de Concepción, Chile.Email: willas@udec.cl/illasw@hotmail.com

2 Profesor de pedagogía en español por la Universidad de Concepción, Chile. Magíster en Literaturas Hispánicas en la Universidad de Concepción, Chile. Email: mauriciograndonate@gmail.com
} 


\section{ABSTRACT}

From the postulates of the Aesthetics of the Reception, it is tried to elucidate a possible horizon of expectations to give an account of comprehensive instances around three texts: Canto III de Maldoror, The flooded house and El crucificado del Conde de Lautréamont, Felisberto Hernández and Mario Levrero respectively, whose reading experience will be reconstructed in the light of the contributions of Darko Suvin, Ángel Rama and Heber Benitez attending three conceptual categories: the rare, fantastic and distanced, which give rise to dialogical possibilities for the concert of other theoretical contributions that Contribute to the configuration of the organizational and argumentative frames that cohesion this discourse, namely: theoretical, contextual and methodological plot. On the contrary, it is intended to foster a reflexive scenario that allows one to notice one of the multiple reading possibilities that these texts display.

Keywords: Rare, fantastic, distanced fictions, wonderful, aesthetic of the reception. 


\section{INTRODUCCIÓN}

\section{Trama teórica}

La definición de "raro" en literatura podría hundir sus raíces en la tradición histórica universal, cuyo empleo se destinaría a agrupar bajo este comodín semántico a aquellas obras que no responden a los esquemas tradicionales y culturales derivados de la ideología, la estética o las formas canónicas de construcción y expresión literaria; sin embargo, Ángel Rama, específicamente en el contemporáneo contexto latinoamericano, en 1966 con su libro Aquí 100 años de raros, se propuso un ejercicio conceptual cristalizado en la selección y muestra de escritores uruguayos que cuyas obras no respondían a ciertos patrones estéticos, sobretodo, aquellos heredados del romanticismo o el realismo. Si bien Rama (1966) considera que la literatura uruguaya reserva una secreta rendija para el fluir de un raro ejercicio escritural, en este aspecto nos dice Benítez (2014) que la rareza: "tiene una impronta de ruptura...que absorbe distintas estrategias de asalto a verosímiles realistas"(p.13).

Es interesante observar cómo lo "raro" no se considera ni fantástico ni propiamente surrealista; en su lugar Rama(1966) prefiere hablar de una "literatura imaginativa" que se construye -según el autor- con cuatro ingredientes fundamentales: formas oníricas, ruptura de la causalidad como ley lógica, aspiración de una asombrosa libertad y preferencia por lo insólito como materia de creación literaria. De esta forma, Benítez (2014) - haciendo referencia a los aportes de Rama- nos señala que las claves de los raros son:

1) el desprendimiento de las relaciones de causalidad; 2) la emergencia de lo insólito ligado a formas oníricas vinculables de una u otra manera con el surrealismo; y 3) la resistencia a la evasión como producto de un reconocimiento crítico de la realidad en el nivel de una compleja vivencia subjetiva, más ligado a un fantástico de compromiso sartreano, cuyo resultado es el de un realismo sin orillas. (p.12)

En el caso de "lo fantástico", la tradición literaria ha vertido ríos de tinta en deslindar rasgos, límites, expresiones y posibilidades de una de las categorías conceptuales más controversiales de la dicotomía racionalista ficción-realidad que intenta clasificar, por un lado obras que den cuenta de lo real o que sus mundos creados entren en una realidad posible; y, obras carentes de toda posibilidad racional en las cuales las leyes de la lógica son transgredidas y en su lugar, operan unos códigos que no podrán 
explicarse más allá de las coordenadas de sentido y significado construidas en el propio texto literario.

El problema colinda con la naturaleza ficcional inherente a la propia materia y sustancia literaria. Pensar por dónde comienza a operar el tejido fantástico en una obra literaria, aún hoy, continúa siendo un desafío que trasciende la diatriba posibilidad-imposibilidad y se instala en la escena de la configuración ficcional que proyecta, en tanto entidad literaria, un mundo posible. El nudo crítico no sería si determinada situación narrativa es o no fantástica, la cuestión es que el relato mismo como creación, se mueve en un terreno de posibilidades, cuyo abono es lo fantástico, indistintamente de la presentación que asuma. Lo que sí es indiscutible es la reacción al realismo como finalidad y necesidad expresiva de la literatura fantástica, también resultan poco cuestionables algunos mecanismos básicos con lo que opera lo fantástico: ruptura de lo que consideramos real, imposibilidad de concebir el acontecimiento dentro de una lógica racional y reconocimiento de la autonomía del mundo posible creado como instancia exclusiva en la que tiene cabida la trama ficcional construida. Este panorama permite dimensionar la valía, significatividad y trascendencia de la conceptualización de fantástico que plantea Benítez (2014) y que resulta a propósito para condensar las contradicciones y esclarecer el ámbito operativo de tal entidad conceptual. Al respecto nos plantea:

Un texto fantástico es, para mí, aquella producción ficcional en la que se establece un problema o conflicto originado entre lo que para ese texto y las ideologías que lo habilitan son lo posible y lo imposible en tanto que acontecimientos, es decir, en tanto que factualidades de presentación excluyente en el interior de ese mundo ficcional y de representación también excluyente en la proyección sobre mundos a los que históricamente atribuimos estatutos de "realidad". (p.14)

Ahora bien, entender lo raro como posibilidad de una literatura imaginativa y, ésta como elemento constituyente de un estamento mayor denominado fantástico, el cual es habitado por el espejeo constante posible e imposible que nos convoca a pensar en una estética no solo alejada del realismo, sino concebida como instancia de ruptura, espacio de contradicción, en fin, ficción distanciada.

Parafraseando a Darko Suvin(1977) se puede entender la ficción distanciada como aquella entidad literaria que no busca reproducir fielmente circunstancias concebibles desde la racionalidad empírica explicada por el sentido común; sino, por el contrario, busca construir mundos radicalmente distintos a la realidad, resistentes a la verificación empírica e imposibles de concebir como respuesta causal en su estructura inter- 
na y en su propuesta externa, generando así una ruptura que la separa de toda tradición posible haciéndola inclasificable por lo indómito, insólito y autónomo de una escritura que, en definitiva, se desprende de toda posibilidad para instalarse en la búsqueda de una libertad absoluta.

Reexplicando el planteamiento de Suvin, nos dice Steimberg (2103): "Suvin propone dividir la ficción según la manera en que las diferentes obras ponen en escena las relaciones de los hombres entre ellos y con el mundo que los rodea" (p.122). Este planteamiento justifica la posibilidad de identificar en la escena literaria, textos cercanos a la ficción realista o textos definitivamente distanciados, irreconciliables con una "textura o superficie empírica"; y, generadores -según Steimberg (ob.cit)- de instancias ficcionales próximas a lo maravilloso. Vale aquí hacer mención al planteamiento que en torno a lo maravilloso, nos formula Chiampi (1983):

Maravilloso es lo "extraordinario", lo "insólito", lo que escapa al curso diario de las cosas y de lo humano... Lejos de ser un modismo terminológico, lo maravilloso ha servido para designar la forma primordial de lo imaginario de obras de todas las latitudes culturales. (pp. 54-55)

De esta forma, puede decirse que la tríada conceptual raro-fantástico-maravilloso convoca la existencia de proyectos escriturales próximos a las coordenadas de ficciones distanciadas, bien de la realidad, la tradición estética, los cánones y de todo marco referencial que intente explicar la pertinencia de la obra en sujeción a determinados esquemas, formas artísticas y posibilidades escriturales cercanas a patrones temáticos, discursivos e ideológicos. Estamos así frente a territorios indómitos en los que son irrenunciables la autonomía y libertad, como únicas dimensiones viables en las que encuentra cabida, efectivamente, la ficción distanciada, ésa misma que se convierte en universo literario de los "raros" uruguayos, específicamente, Lautréamont, Felisberto Hernández y Mario Levrero.

\section{DESARROLLO}

\section{Trama contextual}

Los críticos no dudan en afirmar que la escritura de Mario Levrero tiene como ámbito cohesionador de su propuesta estética, una profunda aspiración de extrañamiento. Sus universos laberínticos apuestan por el inconsciente, el absurdo, la ironía, lo 
fantasmal, la multiplicidad y, quizá, lo esquizofrénico... ¿acaso la realidad no se viste, más de lo que sospechamos, con estos matices? . Es Levrero un recreador permanente de otras posibilidades bien oníricas o disímiles que intentan explicar otra cara de la realidad. De esta forma, sus universos creativos no son más que trampas a la lógica y simbolizan, sin más vueltas, la renuncia de la razón por el triunfo de lo inexplicable, difuso, siniestro y abismal. Sobre este escritor nos dice Veraní (1996)

Pocos narradores hispanoamericanos elaboran un testimonio de descolocación tan radical y perturbador como Levrero. El suyo es un mundo pesadillesco en el cual sucesos anómalos trastornan el acontecer cotidiano, generando procesos interiores atormentados e inestables, portadores de un simbolismo difuso e inaccesible a la razón. (p.45)

Rasgos como pérdida de sentido, realidad laberíntica, extrañamiento, alteración de lo cotidiano, atmósfera inquietante, escritura desquiciante, enigma e irrealidad son instancias conceptuales con las que Veraní (ob.cit) define los universos narrativos por los que transita la escritura de Mario Levrero.

Si los anteriores son elementos recurrentes y caracterizadores de la pluma de Levrero, también resuenan en la producción escritural de Felisberto Hernández. Díaz (1991) le adjudica a este escritor genuino, la presencia, en sus dimensiones narrativas, de una recurrente evocación, de una escritura abismal en la cual lo ambiguo, la desintegración e incoherencia narrativa producen constantes alteraciones expresadas bien en la curiosidad del espectáculo, en la falta de temporalidad, en el desdoblamiento deslocalizado y en el fluir de configuraciones imaginarias que son al mismo tiempo misteriosas, disociadas, ilógicas, extrañas y desconcertantes.

No hay duda que son estos rasgos los que hacen del escritor, una entidad fronteriza que se rehúsa en cada universo ficcional a la clasificación, que no se inscribe en ninguna tradición de "certezas" estéticas y que su búsqueda indómita se balancea en el quiebre permanente de una conciencia transeúnte que se desplaza a un mismo impulso por las fronteras de lo posible e imposible. Fantástico, quizá; imaginativo, tal vez; 0, "raro" en definitiva, es Felisberto Hernández un escritor de lo insólito, un gestor insospechado de lo extraño, trasgresor de posibilidades lógicas; en fin, creador de universos fragmentarios que funden en un mismo crisol las tensiones de lo posible y lo imposible como figuración de una alquimia que a veces es planta, es agua, es un no lugar, o es todo eso proyectado en objetos movidos por un estado excepcional de la conciencia en que la fantasía hace borrosa, e incluso, dudosa, toda posibilidad de realidad. Benítez (2014) acertadamente nos reseña de este escritor, lo siguiente: 
...el lugar de Felisberto ha sido bastante solitario y resulta comprensible como el de una escritura signada por diversas figuraciones de lo insólito...ha trazado un territorio de consolidaciones fronterizas con lo fantástico...En Felisberto Hernández todo se desenvuelve como una fisura de las imágenes de lo cotidiano, que aunque no extingue su lugar, sí disuelve la fuerza de su estabilidad. Los escasos textos que cabría situar como creaciones fantásticas no dejan de ser expresión de una energía doblemente distanciadora... (p.5)

Los elementos que esgrime Benítez, no solo resultan iluminadores, sino que apuestan por esclarecer la escritura autónoma de un extraño universo narrativo movido por "dislocaciones sicológicas - existenciarias"(ob.cit), a cuyas instancias apela Felisberto Hernández como ámbito creativo en tanto deslocalización insólita que trastoca toda posibilidad de certeza a través de un juego excesivo de metaforización en que la realidad desdibuja sus límites y, en una zona fronteriza, se diluye con otra realidad quizá- con otro terreno (desconocido e insospechado) en el cual fluye (como el agua) esa atmósfera de imposibilidad y desconcierto.

Se cierra esta aproximación -no por azar- con el clímax de un escritor límite y distanciado, fronterizo o deslocalizado; en fin, un escritor cuya vida es tan misteriosa, maravillosa o "rara" como su propia obra, específicamente se hace alusión al Conde de Lautréamont (Isidore Ducasse).

Su existencia y su creación han sido motivo de dilatados y profundos estudios, su propuesta estética es debatida entre un neoromanticismo, simbolismo o surrealismo. Los adjetivos que caracterizan su poética se desplazan desde lo incomprensible, inexplicable, fantasmal, abismal, desconcertante, extraño, ilógico e irracional; hasta alusiones un tanto más directas a sus universos narrativos: a) autor misterioso vinculado con lo satánico y lo maldito, b) escritura alucinada cargada de horror, imaginación, fractalidad y desasosiego; y, c)poeta revolucionario que cuya pluma suscita un sentido oculto de imágenes y asociaciones que desembocan en la incertidumbre. En este sentido, Moure (2011) nos dice: "Esta es la gran aportación teórica de Lautréamont... la manifiesta libertad del hombre para crear nuevos mundos de fantasía mediante el dinamismo permanente de lo irracional" (p.2). Por su parte, Fernández (1999) afirma que en Lautréamont: "Su prosa es demasiado fluida, rica, extraña: está impregnada de polivalencias y ambigüedades, de metamorfosis, violencia y transgresiones" (p.57)

Imaginación, extrañeza, ruptura de la lógica, escritura abismal, desconcierto, universo narrativo fronterizo; y, presentación borrosa e imposible desde los códigos de la 
realidad, son solo algunos rasgos que delinean los contornos escriturales de Lautréamont, Felisberto Hernández y Mario Levrero, cuyos contornos alejados de la razón, se refugian en la curiosidad como única tabla de salvación frente a enmarañados universos insólitos que develan, sin muchas opciones, a escritores "raros", en fin, distanciados.

\section{Trama metodológica}

En este escenario, dedicado a la comprensión de los textos a objeto del presente trabajo, resulta necesario hacer evidente tres ideas en torno a la ruta metodológica que opera alrededor del interés aproximativo hacia los textos en cuestión:

En primer lugar, se recurrirá a los postulados de la Estética de la Recepción dado que la aspiración se concentra en plantear un determinado horizonte de expectativas a partir de la experiencia de lectura dinamizada desde la actividad del lector para dar un sentido "posible" y un significado -inacabado- a los espacios indeterminados que el texto proyecta. Al respecto, afirma Iser (1987):

Si el texto es un sistema de estas combinaciones, entonces debe ofrecer un espacio sistémico a quien deba realizar la combinación. Éste es dado por los pasajes vacíos que como determinados espacios en blanco marcan enclaves en el texto, y de esta manera se ofrecen así a ser ocupados por el lector.(p.263)

Es deducible entonces que el interés se concentra en rellenar los espacios vacíos que el documento literario presenta a partir de un rol activo de lectura (segundo aspecto esgrimido para esta explicación metodológica) en el cual quede develada la actividad del lector en la búsqueda de significados que orbitan alrededor de la obra literaria. Nos dice Eco (2000), en este aspecto, lo siguiente:

...Ante todo, porque un texto es un mecanismo perezoso (o económico) que vive de la plusvalía de sentido que el destinatario introduce en él...En segundo lugar, porque, a medida que pasa de la función didáctica a la estética, un texto quiere dejar al lector la iniciativa interpretativa, aunque normalmente desea ser interpretado con un margen suficiente de univocidad. Un texto quiere que alguien lo ayude a funcionar. (p.76)

Como última idea explicativa, es evidente que el interés de lectura asumido se concentra en advertir el efecto que los textos literarios a objeto de estudio, son capaces de suscitar en el lector. Dicho de otro modo, interesa ver cómo el horizonte de expectativas se materializa en el esfuerzo por desentrañar aquellos aspectos "provo- 
cadores o tentadores" con los que la obra cautiva el interés de una genuina y particular experiencia de lectura. Este aspecto es definido por el mismo Iser (1972), a partir de los siguientes enfoques:

Es la virtualidad de la obra la que da origen a su naturaleza dinámica, y ésta a su vez es la condición previa para los efectos que la obra suscita. A medida que el lector utiliza las diversas perspectivas que el texto le ofrece a fin de relacionar los esquemas y las "visiones esquematizadas" entre sí, pone a la obra en marcha, y este mismo proceso tiene como último resultado un despertar de reacciones en su fuero interno. (p.216)

Instancias como inacabado, integrativo y aproximativo definen el proceso comprensivo asumido para "mirar" - apreciar- algunos rasgos temáticos, estéticos o formales que actúan como elementos caracterizadores de la escritura de Lautréamont, Felisberto Hernández y Mario Levrero.

\section{a. Cantos de Maldoror de Lautréamont}

El horizonte de expectativas advertido en la comprensión de esta obra se dinamizará en tres complejos temáticos, cuyo efecto atrae a la experiencia de lectura en el conjunto de transiciones comunicativas que se suscitan en el permanente encuentro lector - texto:

a) La presencia de Dios. Desde el inicio, Dios es una entidad que aparece no sólo personificado, sino evidente a los ojos del autor como malvado, hipócrita y repleto de imperfecciones. Si bien es cierto que la desmitificación no niega del todo la presencia de Dios, antes bien, la corrobora; hay un empeño recurrente por asumirlo como un ser cruel, miserable, perverso y contradictorio: "el Todopoderoso aparece ante mí revestido de sus instrumentos de tortura, en toda la aureola resplandeciente de su horror" (p.118). El autor tiene como empeño castigar a Dios: "Quiero que el Creador contemple, cada hora de su eternidad, la grieta abierta. Es el castigo que le inflijo" (p.120). Este castigo no surge solo desde el arrebato del autor, también se pretende que la conciencia del propio Creador le haga sentir despreciable: "Oh cabello, tú mismo puedes verlo, ipor todos los flancos me siento asaltado por el sentimiento desatado de mi depravación!"(p.140). Y es que, ciertamente la propia conciencia de Dios es cuestionada y puesta en tensión por una actitud ligera de fornicación y ebriedad, de esta forma su figura es degradada a través de una sucesión de conductas penosas (sexo con una prostituta, desolla a un joven, está borracho).

b) Lo grotesco sangriento como testimonio de la crueldad manifiesta en el discurso. 
El escritor recrea con cierta perversión y con actitud contemplativa de sentido macabro y malévolo cómo Maldoror -con aberración- lacera y desagarra el cuerpo de la niña: "De este amplio agujero, retira sucesivamente los órganos interiores; las tripas, los pulmones, el hígado y finalmente el propio corazón" (p.125); o, como la prostituta es "redimida" en el procedimiento de lavar sus entrañas de las impurezas de un cliente ruin: "... atraídos por el olor seminal, la tiraban al suelo...y desmenuzaban, a picotazos, hasta que saliese sangre los labios fláccidos de su hinchada vagina" (p.132). Entre los tantos ejemplos, podemos citar el de la escena en donde el joven es desollado por un verdugo celestial, por un Creador insatisfecho: "Estaba literalmente despellejado de los pies a la cabeza; arrastraba, sobre las losas de la habitación, su piel desollada" (p.136).

c) Lo insólito bajo una aparente normalidad. El autor no solo hace descender a Dios de su inmaculado santuario a rebajarse bebiendo de los mismos excesos de la corrupción humana; sino que debe volver a buscar un cabello olvidado en una "habitación lúgubre, sobre la tarima cubierta de sangre coagulada, de jirones de carne seca...", cuyo cabello amenaza con empañar la imagen excelsa y pura del Creador: "Pero no dejaré de contar a los hombres lo que ocurrió en esta celda. Les daré permiso para arrojar su dignidad cual vestimenta inútil, pues tienen el ejemplo de mi señor". Dios, en un gesto de vergüenza: "... había creído ser el Todopoderoso; pero no; debo humillar la cabeza ante el remordimiento que me grita: "¡No eres más que un miserable!"...". Vuelve para recobrar su cabello como vuelve un criminal hipócrita a borrar la escena de la infamia: "¡No des semejantes saltos! ¡Cállate...cállate!...jsi alguien te oyera!; te colocaré de nuevo entre los otros cabellos...", de esta forma el autor -irónica y paradójicamente- cubre de oscuridad, perversidad y clandestinidad las acciones de una blanca aureola, de un Dios iluminado, de una claridad sublime, impecables y majestuosamente santa: "... pero deja primero que el sol se ponga en el horizonte, para que la noche envuelva tus pasos...".

Estos tres aspectos esbozados en una de las infinitas perspectivas de lectura con las que ha sido reconstruida la experiencia escritural de Lautréamont, demuestra una recreación del horror, un predominio de lo absurdo y una dimensión irracional que hace estallar la conciencia en una dualidad de inacabada resolución: lo posible y lo imposible estrechados por la suerte de lo irónico en un tapiz narrativo que se debate entre la fantasía y la extrañeza para golpear al lector no sólo como transición hermenéutica de lectura, sino golpearlo hasta dejarle sin certezas, sumergido en el horizonte misterioso de una escritura signada por el abismo alucinante de una lógica que no se recobrará jamás. Nos dice en este aspecto Chiampi (1983):

...lo maravilloso [es un]... importante elemento de la época renacentista... y en pleno 
realismo europeo sobrevive en la búsqueda de la sobrerrealidad de Les Chants de Maldoror, de Lautréamont. Tradicionalmente, lo maravilloso es, en la creación literaria, la intervención de seres sobrenaturales, divinos o legendarios...en la acción narrativa 0 dramática...Es identificado muchas veces, con el efecto que provocan tales intervenciones en el oyente o en el lector (admiración, sorpresa, espanto, arrebatamiento). (p.55)

\section{b. La casa inundada de Felisberto Hernández}

En este texto, Hernández presenta una realidad transfigurada en sueño, de esta forma la inestabilidad y lo insólito son expresados en situaciones y personajes que no se asombran ni sorprenden ante las circunstancias que deben enfrentar, así no hay reacción que ponga en crisis o devele el caos de cuanto ocurre.

Con un discurso metaficcional, la historia pone trampas a la memoria, obsesionando así a los personajes (Margarita fue trastornada toda su vida - también es rara de tanto libro), en un constante fluir de la conciencia que se torna materia, atmósfera e ideal de la historia que ya no es solo estética o temática, ahora también es ideológica (cultivar los recuerdos en el agua, el agua penetra el pensamiento, el agua lleva dentro de sí algo).

El narrador se desdobla en personaje; $y$, aun con la excentricidad de los actantes, se trata de recurrir a la objetividad de los sucesos a partir de lo que acredita la ficción. Al indagar sobre la memoria se cae en el misterio, en el espejismo que oculta al amor y en la metaforización de lo concreto, a través de figuraciones insólitas en que lo extraño permite ahogar en el agua al pensamiento, se inunda ahora a la conciencia y al propio discurso narrativo. La única tabla de salvación ante un inminente naufragio es, sin duda, la locura... el absurdo.

Imposible no detenerse en el tema del agua. En la historia, el agua asume la imagen de lo psíquico, de esta forma es el alma y la vida de los personajes, también conjuga en un mismo impulso la simpleza y la complejidad de una búsqueda existencial que asume las veces de un recuerdo diluido, en su imagen líquida, que discurre entre los sueños y secretos del sujeto creador. Al respecto, afirma Lespada (2014):

No sólo la casa está inundada en este texto, es decir, la inundación no se encuentra sólo en el nivel de la anécdota, sino que toda su estructura acusa un permanente desborde asociativo, así como fluye la conciencia del narrador sin fronteras nítidas entre la vigilia y el sueño. La imagen del agua funciona como un gran comunicador y un poderoso solvente de divisiones y compartimientos estancos... El agua, entonces, se constituye en la ley del relato, o mejor aún, en el fluido que arrasa on toda ley o convención, de la misma forma 
que diluye las categorías adentro-afuera. Nada permanece estático ni cerrado ni imperturbable, todo se comunica por el fluido, todo es colmado por el fluido que, al igual que el lenguaje, todo lo alcanza, lo transporta, lo penetra y lo cubre: formas, personajes, pensamientos, imaginación, sueños. (pp. 317-318)

\section{c. La calle de los mendigos de Mario Levrero}

Este relato resulta paradigmático para la comprensión de la obra narrativa de Levrero, puesto que despliega elementos que estarán constantemente presentes en ella, tales como el laberinto (¿o realidad laberíntica?), la alteración de lo cotidiano y la pérdida del sentido. En otras palabras, funciona como síntesis de los procedimientos que singularizan en grado sumo el corpus literario del autor. En cuanto a la pérdida de sentido en el relato, al ser la característica más general, posee una mayor proliferación en cuanto a los análisis que pueda suscitar y por este motivo será nuestro punto de aproximación hacia su lectura con respecto a su pertenencia con lo maravilloso, vale decir, en palabras de Chiampi (1983) lo extraordinario, lo maravilloso. Además, si consideramos la categorización que realiza Neil Cornwell, a partir de los postulados de Todorov, sobre lo maravilloso en cuanto a su concepción de ficción distanciada, diremos que el relato de Levrero constituye una Fairy Story, es decir, aquellas "narraciones que se desarrollan en nuestro mundo, pero con transformaciones múltiples" (Steimberg, 2013:112).

A grandes rasgos, el relato trata acerca de un hombre que quiere encender un cigarrillo y no puede, por lo que se propone buscar el desperfecto. Básicamente, este será el arco argumental de la narración, lo que no hace prever al lector de ningún encuentro con algún elemento insólito, pero es en la búsqueda del narrador protagonista donde vemos el desarrollo paulatino de un extrañamiento dado por el inusual crecimiento del encendedor a medida que lo va desarmando; cabe mencionar la creciente obsesión que se apodera del personaje, ya que lo que en un comienzo era la respuesta lógica a la molestia causada por la avería del encendedor, su insistencia crece a la par que descubre nuevas piezas constituyentes del objeto, esta terminará transformándose en curiosidad por la estructura de algunos encendedores, es decir, el afán de búsqueda/curiosidad se mantiene, al igual que el objeto, no así el foco de la búsqueda. También, debemos tener en cuenta la falta de asombro del protagonista frente al fenómeno en el que se encuentra inmerso, ya que constantemente reflexionará sobre su encendedor y las piezas que lo componen, pero no le llamará la atención el hecho que termine dentro de su objeto, tratando de salir del espacio laberíntico en el que se ha convertido. Quizás, tratamos con un alejamiento sutil en cuanto a la mímesis con el mundo real, cifrada en la acción de prender un cigarrillo, que va 
progresando hasta llegar a un momento en que la lógica racional no sirve para encontrar un sentido a lo que sucede.

De acuerdo a lo anterior, podemos plantear el carácter maravilloso del relato dado por el alejamiento progresivo que se desarrolla en cuanto a la inmersión del hombre en busca del desperfecto y el crecimiento del encendedor. Para ser más específicos, la categoría de fairystory resulta más precisa, ya que considera las diferentes transformaciones que puede llegar a tener una narración a partir de un estado de "normalidad". Son las ramificaciones del encendedor y la imperturbabilidad del hombre los elementos que permiten captar estos conceptos como claves de lectura, teniendo en consideración que la narración no se agota en ellas, puesto que es lo insólito, lo indómito, lo autónomo que caracteriza la búsqueda de la libertad absoluta que señalara Duvin en su concepción de ficción distanciada, lo que mantiene la frescura del relato.

\section{CONCLUSIONES}

Pensar en productos acabados, investigaciones cerradas o marcos conclusivo rígidos es una aventura peligrosa, sobre todo si nos encontramos examinando productos literarios. No obstante, en ejercicio a una comunicación académica cónsona con parámetros establecidos por la misma comunicabilidad de la ciencia, nos arriesgamos a precisar tres ideas que guiaron el curso de este documento, que podrían apostar por nuevos debates y que posibilitan una mirada más a propósitos de los autores abordados y de su obra:

1. Entendemos que, ante la carencia de mecanismos rígidos para determinar los límites de lo fantástico y ante la presencia de diversos casos de escritura "rara" que han plagado nuestras literaturas, existe un universo de ficciones distanciadas que además de no admitir fórmulas de encasillamientos innecesarios, abrigan en su episteme casos particulares de una escritura que se mueve en zonas límite, orbitando alrededor de estrategias, temas y propuestas estéticas que se ubican en la frontera, en la extrañeza; en fin, en el asombro, la perplejidad y el desconcierto.

2. Específicamente en el caso de la literatura uruguaya, nos atrevemos, con fundamento en los planteamientos de Benítez (ob.cit), a ubicar a los escritores y las obras trabajadas en esa franja de escritura distanciada. Casos de una literatura que escapa a las clasificaciones desgastadas, a los convencionalismos temáticos; obras que apuestas por una reinvención de lo fantástico, por una propuesta artísti- 
ca sostenida en el absurdo, la imaginación extrema, lo irracional y ese interés de hacer cotidiano ese extravío de las certezas que exacerba el juego de la incertidumbre.

3. Sirva este trabajo como provocación para continuar el desarrollo investigativo, la lectura y la discusión en torno a tres grandes complejos temáticos: las ficciones distanciadas, la obra de Lautréamont, Levrero y Hernández; y la presencia de estos casos de escritura "rara" en el amplio mapa de nuestra literatura latinoamericana. La idea sería advertir a la crítica que esta debate continúa abierto.

\section{REFERENCIAS BIBLIOGRÁFICAS}

Benítez, H. (2014). Raros y fantásticos: perspectivas teóricas. En [Sic]Revista arbitrada de la asociación de profesores de literatura del Uruguay. Año IV-Nº10 (pp.10-15).

Chiampi, I. (1983). El realismo maravilloso. Caracas: Monte Ávila Editores.

Díaz, J. (1991). FelisbertoHernández. El espectáculo imaginario, I. Montevideo: Ed. Arca.

Fernández, R. (1999). La poética de Lautrémaont y la escritura vanguardista. En Théléme. Revista Complutense de Estudios Franceses. N¹4. (pp 57-68). Disponible en: http://revistas.ucm.es/index.php/THEL/article/viewFile/THEL9999110057A/33691. [Consulta 28/06/2015]

Genette, G. (1989). Palimpsestos. La literatura en segundo grado. Madrid: Ed. Taurus.

Iser, W. (1972). El proceso de lectura: enfoque fenomenológico. En: Estética de la Recepción. (pp 215-243)

Iser, W. (1987). El acto de leer. Madrid: Ed. Taurus.

Lespada, G. (2014). Carencia y literatura. El procedimiento narrativo de Felisberto Hernández. Buenos Aires: Ed. Corregidor

Moure, I. (2011). Sobre el Conde de Lautrémaont y el arte surrealista. En Revista de la Asociación Aragonesa de Críticos de Arte. Número 14. Documento disponible en: http://www.aacadigital.com/contenido.php?idarticulo=447 [Consulta 29/06/2015]

Rama, A. (1996). Aquí cien años de raros. Montevideo: Ed. Arca

Steimberg. A. (2013). Literaturas de la certeza y de la duda ontológica. Propuesta clasificadora para la ficción distanciada. En Brumal. Revista de investigación sobre lo fantástico. Volumen $1 \mathrm{~N}^{\circ}$ 1.(pp.115-134). Disponible en: dialnet.unirioja.es/descarga/articulo/4863454.pdf [Consulta 28/06/2015]

Suvin, D. (1977). Pour une poétique de la science-fiction. Études en théorie et en histoired'ungenrelittéraire.Montreal: Presses de la Université du Québec.

Veraní, H. (1996). Mario Levrero: aperturas sobre el extrañamiento. En Nuevo texto crítico. Volumen VIII N 16/17. (pp.45-58) 